\title{
Sex-Specific Influence of the SCARBI Rs5888
}

SNP on the Serum Lipid Response to Atorvastatin in Patients with Acute Coronary Syndrome Undergoing Percutaneous Coronary Intervention

This article was published in the following Dove Press journal:

Pharmacogenomics and Personalized Medicine

\section{Dong-Feng $\mathrm{Wu}\left(\mathbb{D}^{1, *}\right.$ \\ Dan $\operatorname{Lin}^{2, *}$ \\ Feng Lu' \\ Qin-Chen Liao' \\ Yu-Juan $\mathrm{Wu}^{\prime}$ \\ Zhou Wang' \\ Kun Yu' \\ Wei-Jun Li' \\ Jin-Long Deng $\mathbb{D}^{\prime}$}

'Department of the Geriatric Cardiology, People's Hospital of Guangxi Zhuang Autonomous Region, Nanning 53002I, Guangxi, People's Republic of China;

${ }^{2}$ Department of the First Comprehensive Clinic, The Affiliated Stomatology Hospital of Guangxi Medical University, Nanning 53002I, Guangxi, People's Republic of China

*These authors contributed equally to this work

\begin{abstract}
Background: Epidemiological studies have shown that there are sex differences in blood lipid levels and lipid responses to statins. Previous studies have shown that the rs5888 single nucleotide polymorphism (SNP) in the scavenger receptor class B type 1 (SCARBI) gene is associated with serum lipid levels in a sex-specific manner. The present study was undertaken to detect the sex-specific influence of the SCARB1 rs5888 SNP on the serum lipid response to atorvastatin in patients with acute coronary syndrome (ACS) undergoing percutaneous coronary intervention (PCI).
\end{abstract}

Methods: A total of 158 unrelated ACS patients (108 males, 50 females) were enrolled, and all patients received atorvastatin $20 \mathrm{mg} /$ daily after PCI. Genotyping of the rs5888 SNP was performed by polymerase chain reaction and direct sequencing. Serum lipid profiles were determined before treatment and after an average follow-up time of one year.

Results: The baseline serum total cholesterol (TC), low-density lipoprotein cholesterol (LDL-C), high-density lipoprotein cholesterol (HDL-C) and apolipoprotein (Apo)AI levels were higher in females than in males $(\mathrm{P}<0.05)$. After treatment with atorvastatin, serum TC, LDL-C, and ApoB were decreased, and ApoAI was increased $(\mathrm{P}<0.05)$. The effects of atorvastatin on serum lipid levels were different between males and females, and females had greater decreases in TC, LDL-C and ApoB levels than males $(\mathrm{P}<0.05)$. The genotypic frequencies of the rs5888 SNP were not different between males and females. The atorvastatin response was not associated with the rs5888 SNP in males $(\mathrm{P}>0.05)$. Nonetheless, in female individuals carrying the rs5888 T-allele, we observed a greater reduction in TC, LDL$\mathrm{C}$, and ApoB levels after the use of $20 \mathrm{mg} /$ day atorvastatin $(\mathrm{P}<0.05)$.

Conclusion: This study indicates that the SCARB1 rs5888 T-allele was associated with a greater reduction in serum TC, LDL-C, and ApoB after atorvastatin treatment in female patients with ACS undergoing PCI.

Keywords: sex-specific, lipid, atorvastatin, scavenger receptor class B type 1, polymorphism, coronary artery disease

\section{Introduction}

Dyslipidemia, including elevated serum levels of total cholesterol (TC), triglycerides (TGs), low-density lipoprotein cholesterol (LDL-C), and apolipoprotein (Apo) B or low levels of high-density lipoprotein cholesterol (HDL-C) and ApoAI, is one of the most important modifiable risk factors for coronary artery disease (CAD) ${ }^{1-3}$ Statins are 3-hydroxy-3-methylglutaryl coenzyme A reductase inhibitors that
Correspondence: Jin-Long Deng Department of the Geriatric Cardiology, People's Hospital of Guangxi Zhuang Autonomous Region, 6 Taoyuan Road, Nanning 53002I, Guangxi, People's Republic of China

Email djl_gx@I63.com
Pharmacogenomics and Personalized Medicine 2020:|3 553-56 | 
mainly reduce LDL-C levels and TC levels, and the efficacy and safety of statins for both primary and secondary cardiovascular disease prevention have been established in large randomized clinical trials (RCTs). ${ }^{4}$ In these RCTs, initiation of moderate-intensity therapy (reducing LDL-C by approximately $30 \%$ to $<50 \%$ ) or high-intensity statin therapy (reducing LDL-C by approximately $\geq 50 \%$ ) is a critical factor in reducing atherosclerotic cardiovascular disease (ASCVD) events. ${ }^{5}$ Therefore, statin therapy is recommended for individuals with increased ASCVD risk who are most likely to experience a net benefit in terms of the potential for ASCVD risk reduction and for adverse effects. ${ }^{5}$ Lipid metabolism is a complex trait resulting from genetic factors and multiple environmental factors; there is also a high degree of variability in the clinical response to statins, and many studies have indicated that this variability is due to genetic factors. ${ }^{6,7}$

Scavenger receptor class B type 1 (SCARB1), also known as $S R-B I$, is an HDL receptor that binds HDL-C with high affinity, mediates selective cholesterol uptake of HDL, and plays an important role in reverse cholesterol translation. ${ }^{8}$ Previous studies have shown its importance in lipoprotein metabolism and atherosclerosis in mouse models. ${ }^{9,10}$ The rs5888 single nucleotide polymorphism (SNP), a "C" to " $\mathrm{T}$ " substitution at amino acid 350 in exon 8 of $S C A R B 1$, has been associated with serum lipid levels. ${ }^{11,12}$ However, the SCARB1 rs5888 SNP is associated with the lipid-lowering atorvastatin response in hypercholesterolemic individuals. ${ }^{13}$ Moreover, our previous studies have shown that the rs5888 SNP in the $S C A R B 1$ gene is associated with serum lipid levels in a sex-specific manner in the general Chinese population and CAD patients. ${ }^{14,15}$ It was reported that sex-based variations exist in the pathophysiology, symptoms, presentation, efficacy of diagnostic tests, and response to pharmacological interventions. ${ }^{16}$ Thus, the present study was undertaken to analyze the sex differences in the SCARB1 rs5888 SNP in terms of the serum lipid response to atorvastatin in patients with acute coronary syndrome (ACS) undergoing percutaneous coronary intervention (PCI).

\section{Materials and Methods}

\section{Patients}

A total of 158 patients, including 108 males and 50 females who were diagnosed with ACS and received PCI treatment in the geriatric cardiovascular department of Guangxi Zhuang Autonomous Region People's Hospital from January 2016 to
January 2018, were enrolled in this study. The enrolled subjects received a dose of $20 \mathrm{mg} /$ day atorvastatin for a long period of time after being diagnosed with ACS. Subjects with congenital heart disease, cardiomyopathy, valvular disease, autoimmune disease and type I diabetes mellitus were excluded. Medical history data, including data on diabetes, hypertension and other cardiovascular diseases, were collected for all selected subjects. The physical examination included assessments of blood pressure, height and weight, and body mass index (BMI) was calculated according to height and weight. All patients signed informed consent forms when they were admitted to the hospital. The study was approved by the Ethics Committee of Guangxi Zhuang Autonomous Region People's Hospital. ${ }^{17}$

\section{Drug Information}

All selected patients were routinely given 20-mg tablets of atorvastatin (Lipitor, Pfizer Pharmaceutical Factory) every night after admission. All patients received two types of antiplatelet drugs (clopidogrel $75 \mathrm{mg} / \mathrm{d}$ or ticagrelor $90 \mathrm{mg}$ bid plus aspirin $100 \mathrm{mg} / \mathrm{d}$ ), and they were treated with atorvastatin $20 \mathrm{mg} / \mathrm{night}$ for an extended period of time after PCI.

\section{Genotyping and Biochemical Analysis}

On the second day after admission, antecubital venous blood from the forearm was taken on an empty stomach and sent to the Clinical Laboratory Center of Guangxi People's Hospital to measure blood lipids. Biochemical indicators were measured with a Beckman Coulter AU 5831 automatic biochemical analyzer (Beckman Coulter Inc, Brea, CA USA). TC, TG, HDL-C and LDL-C levels in the samples were determined by enzymatic methods with commercially available kits. Serum ApoAI and ApoB levels were measured by immunoturbidimetric immunoassay. ${ }^{17}$ Genomic deoxyribonucleic acid (DNA) was extracted from peripheral blood leukocytes using the phenol-chloroform method. Genotyping of the SCARB1 rs5888 SNP was performed by polymerase chain reaction ${ }^{14,15}$ and direct sequencing.

\section{Statistical Analyses}

The statistical analyses were carried out using the statistical software package SPSS 22.0 (SPSS Inc., Chicago, Illinois). The standard goodness-of-fit test was used to test the HardyWeinberg equilibrium. A chi-square analysis was used to evaluate the difference in genotype distribution and ratio between the groups. A $t$-test was used to evaluate the difference in general characteristics between males and females. Repeated measurement analysis of variance was used to test 
the changes in blood lipid parameters before and after treatment. The difference in lipid levels across genotypes was tested by analysis of covariance. The changes in serum lipid levels between baseline and 1 year according to genotypes were tested by ANOVA or analysis of covariance. TG did not follow a normal distribution; the values are expressed as medians (25th and 75th percentiles) and were logtransformed for the analysis. Sex, age, BMI, blood pressure, alcohol consumption, and cigarette smoking were adjusted for in the statistical analysis, and $\mathrm{P}<0.05$ was considered statistically significant.

\section{Results}

\section{Clinical Characteristics of Males and Females}

The baseline characteristics of the male and female patients are shown in Table 1. The mean age, BMI, duration of treatment, and ratios of patients with hypertension, hypercholesterolemia or diabetes were not different between males and females $(\mathrm{P}>0.05$ for all), and the percentage of subjects who consumed alcohol or smoked cigarettes was higher among males than females $(\mathrm{P}<0.05)$.

\section{Different Serum Lipid Responses to Atorvastatin Between Males and Females}

As shown in Table 2. The baseline serum TC, LDL-C, HDL-C and ApoAI levels were significantly higher in females than in males $(\mathrm{P}<0.05)$. After treatment with atorvastatin, serum TC, LDL-C, and ApoB decreased, and ApoAI increased in both males and females $(\mathrm{P}<0.05)$. However, there were significant differences between males and females in terms of serum TC, LDL-C and ApoB levels in response to atorvastatin, and after atorvastatin treatment, the TC, LDL-C and ApoB levels in females decreased more than those in males $(\mathrm{P}<0.05)$.

\section{Genotypic and Allelic Frequencies Between Males and Females}

The genotypic and allelic frequencies of the SCARB1 rs5888 SNP are presented in Table 3. The genotype distribution was concordant with the Hardy-Weinberg proportions. There were no significant differences in the genotypic and allelic frequencies between males and females $(P>0.05)$.

\section{Influence of the SCARBI Rs5888 SNP on Serum Lipid Levels in Response to Statins}

Table 4 shows the lipid and lipoprotein levels in baseline and after atorvastatin therapy. There was a significant effect of the rs5888 genotype or T-allele on serum lipid levels at baseline (TC, LDL-C, HDL-C, ApoAI and ApoB) and posttreatment (HDL-C, ApoAI and ApoB). The ANOVA revealed that there were significant changes in the levels of TGs after atorvastatin treatment according to genotypes $(P=0.009)$, but these changes were not statistically significant after adjustments were made for sex, age, BMI, blood pressure, alcohol consumption, and cigarette smoking $(P>0.05)$ (Table 4$)$.

\section{Influence of the SCARBI Rs5888 SNP on Serum Lipid Levels in Response to Statins Stratified by Sex}

Because there are obvious sex differences in the response of blood lipids to atorvastatin in our study, we further analyzed the effect of the gene-atorvastatin interaction on blood lipids according to sex. As shown in Tables 5 and 6,

Table I General Characteristics of Males and Females

\begin{tabular}{|l|l|l|l|l|}
\hline Parameter & Males & Females & $t / \chi^{2}$ & $P$ \\
\hline Number & 108 & 50 & & \\
Age (years) & $61.20 \pm 12.17$ & $64.82 \pm 7.22$ & -1.970 & $0.05 \mathrm{I}$ \\
BMI & $23.64 \pm 3.73$ & $23.30 \pm 3.52$ & 0.582 & 0.562 \\
Hypertension & $42(38.9 \%)$ & $20(40.0 \%)$ & 0.018 & 0.894 \\
Diabetes & $6(5.6 \%)$ & $6(12 \%)$ & 2.022 & 0.155 \\
Hypercholesterolemia & $42(38.9 \%)$ & $26(52 \%)$ & 2.397 & 0.122 \\
Smoking status & $32(29.6 \%)$ & $0(0 \%)$ & 18.577 & 0.000 \\
Alcohol consumption & $38(35.2 \%)$ & $3(6 \%)$ & 15.150 & 0.000 \\
Duration of treatment (months) & $11.38 \pm 3.54$ & $11.86 \pm 2.45$ & 0.866 & 0.387 \\
\hline
\end{tabular}

Abbreviations: $t$, value of $t$-test for two independent samples; $\chi^{2}$, value of the chi-square test; BMI, body mass index; $P, \mathrm{P}$ value of chi-square test and $t$-test between males and females. 
Table 2 Different Serum Lipid Responses to Atorvastatin Between Males and Females

\begin{tabular}{|c|c|c|c|c|c|c|c|}
\hline & \multicolumn{2}{|l|}{ All } & \multicolumn{2}{|l|}{ Males } & \multicolumn{2}{|l|}{ Females } & \multirow[t]{2}{*}{$P$} \\
\hline & Baseline & Treatment & Baseline & Treatment & Baseline & Treatment & \\
\hline $\mathrm{TC}(\mathrm{mmol} / \mathrm{L})$ & $4.75 \pm 1.10$ & $3.97 \pm 0.92^{*}$ & $4.50 \pm 0.98$ & $3.96 \pm 1.00 *$ & $5.28 \pm 1.15^{\dagger}$ & $4.0 I \pm 0.7 I^{*}$ & 0.000 \\
\hline $\mathrm{TG}(\mathrm{mmol} / \mathrm{L})$ & $1.28(0.98-1.86)$ & I.32 (0.95-I.89) & $1.27(0.99-1.73)$ & $1.28(1.01-1.97)$ & $1.42(0.96-2.23)$ & I.44 (0.87-I.76) & 0.198 \\
\hline HDL-C (mmol/L) & $1.09 \pm 0.28$ & $1.10 \pm 0.27$ & $1.02 \pm 0.22$ & $1.04 \pm 0.27$ & $1.26 \pm 0.32^{\dagger}$ & $1.21 \pm 0.25$ & 0.120 \\
\hline LDL-C (mmol/L) & $2.96 \pm 0.84$ & $2.28 \pm 0.64 *$ & $2.82 \pm 0.70$ & $2.32 \pm 0.67^{*}$ & $3.27 \pm 1.02^{\dagger}$ & $2.19 \pm 0.57^{*}$ & 0.000 \\
\hline ApoAl (g/L) & $1.15 \pm 0.24$ & $\mid .21 \pm 0.2 I^{*}$ & $1.08 \pm 0.18$ & $1.16 \pm 0.21 *$ & $1.29 \pm 0.29^{\dagger}$ & $1.30 \pm 0.18$ & 0.059 \\
\hline ApoB $(g / L)$ & $0.96 \pm 0.23$ & $0.77 \pm 0.18^{*}$ & $0.94 \pm 0.21$ & $0.79 \pm 0.18^{*}$ & $1.01 \pm 0.25$ & $0.73 \pm 0.16 *$ & 0.001 \\
\hline
\end{tabular}

Notes: *Compared with before treatment, $\mathrm{P}<0.00 \mathrm{I}$, repeated measurement analysis of variance was used to test the changes in blood lipid parameters before and after treatment. †Compared with males at baseline, $\mathrm{P}<0.00 \mathrm{I}$, the difference in lipid levels between males and females was tested by analysis of covariance; age, BMI, blood pressure, alcohol consumption, and cigarette smoking were adjusted for in the statistical analysis. TG did not follow a normal distribution, the values are expressed as medians (25th and 75th percentiles) and was log-transformed for the analysis. P: difference in changes of serum lipid levels after atorvastatin treatment between males and females, was tested by analysis of covariance; age, BMI, blood pressure, alcohol consumption, and cigarette smoking were adjusted for in the statistical analysis.

Abbreviations: TC, total cholesterol; TGs, triglycerides; HDL-C, high-density lipoprotein cholesterol; LDL-C, low-density lipoprotein cholesterol; ApoAI, apolipoprotein $\mathrm{Al}$; ApoB, apolipoprotein B.

Table 3 The Genotype and Allele Frequencies of the SCARBI Rs5888 SNP Between Males and Females

\begin{tabular}{|l|l|l|l|l|l|}
\hline \multirow{2}{*}{ Group } & \multirow{2}{*}{$\mathbf{n}$} & \multicolumn{2}{|l|}{ Genotype } & \multirow{2}{*}{$\begin{array}{l}\text { T-Allele } \\
\text { Frequency }\end{array}$} \\
\cline { 3 - 6 } & & $\mathbf{C C}$ & $\mathbf{C T}$ & $\mathbf{T T}$ & \\
\hline $\begin{array}{l}\text { Male } \\
\begin{array}{l}\text { Female } \\
\chi^{2}\end{array}\end{array}$ & $\begin{array}{l}108 \\
50\end{array}$ & $\begin{array}{l}58(0.537) \\
22(0.44)\end{array}$ & $\begin{array}{l}44(0.407) \\
24(0.48) \\
1.377\end{array}$ & $\begin{array}{l}6(0.056) \\
4(0.08)\end{array}$ & $\begin{array}{l}56(0.259) \\
32(0.32) \\
1.255\end{array}$ \\
\hline$P$ & - & 0.502 & & 0.267 \\
\hline
\end{tabular}

Abbreviations: $\chi^{2}$, value of the chi-square test; $P, P$ value of chi-square test between males and females.

there were significant effects of the genotype on serum lipid levels at baseline in females (TC, LDL-C, ApoAI and ApoB) and males (TC, TGs, LDL-C, ApoAI and ApoB) and at posttreatment in females (LDL-C and ApoAI) and males (HDL-C, ApoAI and ApoB). There were significant changes in the levels of TC, LDL-C and ApoB after atorvastatin treatment according to genotype (TC) or T-allele (TC, LDL-C and ApoB) by ANOVA in females, but not in males. These differences remained significant after adjustments were made for age, BMI, blood pressure, alcohol consumption, and cigarette smoking. Female individuals carrying the rs5888 T-allele (CT and TT) had a greater reduction in TC, LDL-C, and $\mathrm{ApoB}$ after $20 \mathrm{mg}$ /day atorvastatin $(P<0.05)$.

\section{Discussion}

In the present study, the serum lipid levels were different between males and females, and the baseline serum TC and LDL-C levels, as well as HDL-C and ApoAI, were higher in females than in males. Consistently, among patients with ischemic stroke or acute myocardial infarction in China, female patients also have significantly higher TC, LDL-C and HDL-C levels. ${ }^{18,19}$ Men and women show significant differences regarding the risk of cardiovascular disease (CVD) development. ${ }^{20}$ At any given age, the risk of CVD among women is one-third to one-half that of men. ${ }^{21}$ Women often present with more comorbidities and experience worse CAD outcomes than men. ${ }^{22}$ Although women aged $20-50$ years tend to have more favorable lipid profiles than men, cholesterol levels increase in women after the onset of menopause but remain steady in men. ${ }^{23,24}$ In our study, the average age of female patients was 64 years, and most of them were postmenopausal. Therefore, this result suggests the loss of a cardioprotective effect in postmenopausal women and that the increased TC and LDL-C levels in postmenopausal women should be given more attention to prevent the increased prevalence of CAD.

Statin therapy is generally recommended to reduce the risk of CVD in both sexes. ${ }^{5}$ However, regarding lipid changes, sex differences in the response to statin therapy have not been well reported. Many of the trials that have established the efficacy and safety of statins were conducted predominantly or entirely in men, with results extrapolated to women. Additional research is needed to guide clinical recommendations that are specific to women. ${ }^{25}$ In the present study, although females had higher levels of TC and LDL-C, there were significant differences in the serum TC, LDL-C and ApoB levels in response to atorvastatin between males and females. After atorvastatin treatment, the TC, LDL-C and ApoB levels in females decreased more than those in males. However, 
Table 4 Influence of the SCARBI Rs5888 SNP on Serum Lipid Levels in Response to Statins

\begin{tabular}{|c|c|c|c|c|c|c|c|}
\hline Genotypes & Period & TC (mmol/L) & TG (mmol/L) & HDL-C (mmol/L) & LDL-C (mmol/L) & ApoAl (g/L) & ApoB (g/L) \\
\hline \multirow[t]{2}{*}{ CC (80) } & Baseline & $4.5 I \pm 0.95$ & $1.26(0.95-1.75)$ & $1.04 \pm 0.29$ & $2.82 \pm 0.7 \mathrm{I}$ & $1.09 \pm 0.25$ & $0.95 \pm 0.20$ \\
\hline & I year & $3.88 \pm 0.75$ & $1.33(1.06-1.89)$ & $1.04 \pm 0.24$ & $2.21 \pm 0.55$ & $1.16 \pm 0.16$ & $0.77 \pm 0.17$ \\
\hline \multirow[t]{2}{*}{ CT (68) } & Baseline & $4.88 \pm 1.20$ & $1.42(1.06-1.86)$ & $1.17 \pm 0.27$ & $3.03 \pm 0.94$ & $1.23 \pm 0.22$ & $0.95 \pm 0.25$ \\
\hline & I year & $4.03 \pm 1.13$ & $\mathrm{I} .42(0.9 \mathrm{I}-2.0 \mathrm{I})$ & $1.18 \pm 0.30$ & $2.3 I \pm 0.75$ & I. $27 \pm 0.24$ & $0.74 \pm 0.18$ \\
\hline \multirow[t]{2}{*}{ TT (I0) } & Baseline & $5.70 \pm 0.90$ & $2.58(1.51-2.95)$ & $1.03 \pm 0.12$ & $3.67 \pm 0.58$ & $1.08 \pm 0.10$ & $1.20 \pm 0.20$ \\
\hline & I year & $4.35 \pm 0.23$ & $1.01(0.84-1.50)$ & $1.05 \pm 0.16$ & $2.65 \pm 0.23$ & $1.13 \pm 0.23$ & $0.93 \pm 0.17$ \\
\hline $\mathrm{PI}$ & - & 0.003 & 0.109 & 0.014 & 0.010 & 0.001 & 0.003 \\
\hline P2 & - & 0.253 & 0.444 & 0.011 & 0.085 & 0.002 & 0.008 \\
\hline P3 & - & 0.163 & 0.009 & 0.952 & 0.368 & 0.728 & 0.367 \\
\hline P4 & - & 0.244 & 0.054 & 0.905 & 0.503 & 0.811 & 0.488 \\
\hline \multirow[t]{2}{*}{ CT/TT (78) } & Baseline & $4.99 \pm 1.19$ & $1.43(1.06-2.18)$ & $1.15 \pm 0.26$ & $3.11 \pm 0.93$ & $1.21 \pm 0.22$ & $0.98 \pm 0.26$ \\
\hline & I year & $4.07 \pm 1.06$ & $\mathrm{I} .32(0.87-2.0 \mathrm{I})$ & $1.16 \pm 0.29$ & $2.36 \pm 0.72$ & $1.26 \pm 0.24$ & $0.77 \pm 0.19$ \\
\hline P5 & - & 0.012 & 0.198 & 0.022 & 0.045 & 0.002 & 0.479 \\
\hline P6 & - & 0.187 & 0.557 & 0.010 & 0.124 & 0.006 & 0.966 \\
\hline P7 & - & 0.148 & 0.095 & 0.833 & 0.304 & 0.429 & 0.297 \\
\hline P8 & - & 0.240 & 0.278 & 0.724 & 0.468 & 0.529 & 0.436 \\
\hline
\end{tabular}

Notes: PI; difference in lipid levels across genotypes at baseline (tested by analysis of covariance. Sex, age, BMI, blood pressure, alcohol consumption, and cigarette smoking were adjusted for in the statistical analysis). P2; difference in lipid levels across genotypes measured at I year (tested by analysis of covariance. Sex, age, BMI, blood pressure, alcohol consumption, and cigarette smoking were adjusted for in the statistical analysis). P3; change in levels of serum lipids between baseline and I-year levels according to genotypes (tested by ANOVA). P4; change in levels of the serum lipid between baseline and I-year level according to genotypes (tested by analysis of covariance. Sex, age, BMI, blood pressure, alcohol consumption, and cigarette smoking were adjusted for in the statistical analysis). P5; difference in lipid levels between the CC genotype and T-allele at baseline (tested by analysis of covariance. Sex, age, BMI, blood pressure, alcohol consumption, and cigarette smoking were adjusted for in the statistical analysis). P6; difference in lipid levels between the CC genotype and T-allele measured at I year (tested by analysis of covariance. Sex, age, BMI, blood pressure, alcohol consumption, and cigarette smoking were adjusted for in the statistical analysis). P7; change in levels of the serum lipid between baseline- and I-year levels according to the T-allele and the CC genotype (tested by ANOVA). P8; change in levels of the serum lipid between baseline- and I-year levels according to the T-allele and the CC genotype adjusted for covariates (tested by analysis of covariance. Sex, age, BMI, blood pressure, alcohol consumption, and cigarette smoking were adjusted for in the statistical analysis). TG did not follow a normal distribution; the values are expressed as medians (25th and 75th percentiles) and were log-transformed for the analysis.

Abbreviations: TC, total cholesterol; TGs, triglycerides; HDL-C, high-density lipoprotein cholesterol; LDL-C, low-density lipoprotein cholesterol; ApoAl, apolipoprotein $\mathrm{Al}$; ApoB, apolipoprotein B.

a previous study indicated that statin treatment has a reduced effectiveness in improving the plasma lipid profile in dyslipidemic women compared to men, ${ }^{26}$ and the lipid-lowering treatment goal attainment rate is lower for women than for men undergoing stable lipid-lowering treatment, especially in the high- and very high-risk groups in mainland China. ${ }^{27,28}$ To explain these controversies, we must understand that the effect of statins on serum lipid reduction is influenced by baseline lipid levels, which were relatively high in females in our study. This would lead to efficient atorvastatin therapy in females and less efficient statin therapy in males, among whom the baseline lipid level is lower. The effect of statins on lipid reduction may also influenced by genetic factors. ${ }^{13}$

The association between the $S C A R B 1$ rs5888 SNP and serum lipid levels has been described in several previous studies. Some have shown that the SCARB1 rs5888 SNP T-allele is associated with increased serum HDL-C levels ${ }^{12,29-33}$ and decreased serum non-HDL-C concentrations $^{11,30}$ and therefore has an atheroprotective effect. However, other studies found that this SNP T-allele has a proatherosclerotic serum lipid profile. ${ }^{12,33}$ In the present study, genotype had significant effects on serum lipid levels at baseline and posttreatment. Subjects with the CT/TT genotype had higher TC, LDL-C, HDL-C, ApoAI and ApoB levels at baseline and higher HDL-C, ApoAI and ApoB levels at posttreatment than those with the $\mathrm{CC}$ genotype. This finding suggests that $S C A R B 1$ rs5888 plays an important role in lipid metabolism. However, whether the $S C A R B 1$ rs5888 SNP influenced serum lipid levels in response to statin treatment needed to be evaluated; thus, we determined whether the lipid response to atorvastatin was associated with the rs5888 SNP. We did not find these associations in our population of males and females after adjusting for confounding factors. We then analyzed the association between the lipid response to atorvastatin and the rs5888 SNP according to sex and that there were significant associations between SCARB1 rs5888 $\mathrm{T}$ and serum TC, LDL-C and 
Table 5 Influence of the SCARBI Rs5888 SNP on Serum Lipid Levels in Response to Statins in Males

\begin{tabular}{|c|c|c|c|c|c|c|c|}
\hline Genotypes & Period & $\mathrm{TC}(\mathrm{mmol} / \mathrm{L})$ & TG (mmol/L) & HDL-C (mmol/L) & LDL-C (mmol/L) & ApoAl (g/L) & ApoB (g/L) \\
\hline \multirow[t]{2}{*}{ CC (58) } & Baseline & $4.43 \pm 0.96$ & $1.26(0.93-1.66)$ & $0.98 \pm 0.24$ & $2.82 \pm 0.69$ & $1.04 \pm 0.21$ & $0.96 \pm 0.20$ \\
\hline & I year & $3.90 \pm 0.84$ & $1.28(1.07-1.90)$ & $1.00 \pm 0.25$ & $2.30 \pm 0.54$ & $1.12 \pm 0.17$ & $0.80 \pm 0.17$ \\
\hline \multirow[t]{2}{*}{ CT (44) } & Baseline & $4.44 \pm 0.92$ & $1.26(1.06-1.67)$ & $1.08 \pm 0.20$ & $2.73 \pm 0.68$ & $1.12 \pm 0.14$ & $0.88 \pm 0.20$ \\
\hline & I year & $3.97 \pm 1.26$ & $\mathrm{I} .24(0.9 \mathrm{I}-2.0 \mathrm{I})$ & $1.12 \pm 0.29$ & $2.30 \pm 0.83$ & $1.22 \pm 0.23$ & $0.73 \pm 0.17$ \\
\hline \multirow[t]{2}{*}{ TT (6) } & Baseline & $5.56 \pm 1.18$ & $2.58(1.73-3.02)$ & $0.99 \pm 0.10$ & $3.50 \pm 0.70$ & $1.10 \pm 0.06$ & $1.21 \pm 0.25$ \\
\hline & I year & $4.49 \pm 0.06$ & $1.13(1.01-2.6 \mathrm{I})$ & $0.93 \pm 0.10$ & $2.80 \pm 0.15$ & $1.04 \pm 0.27$ & $1.02 \pm 0.16$ \\
\hline PI & - & 0.048 & 0.024 & 0.120 & 0.048 & 0.081 & 0.001 \\
\hline P2 & - & 0.404 & 0.981 & 0.044 & 0.228 & 0.013 & 0.000 \\
\hline P3 & - & 0.541 & 0.104 & 0.607 & 0.722 & 0.203 & 0.906 \\
\hline P4 & - & 0.618 & 0.245 & 0.618 & 0.725 & 0.241 & 0.788 \\
\hline \multirow[t]{2}{*}{ CT/TT (50) } & Baseline & $4.58 \pm 1.01$ & $1.43(1.15-1.87)$ & $1.06 \pm 0.20$ & $2.82 \pm 0.72$ & $1.12 \pm 0.14$ & $0.92 \pm 0.23$ \\
\hline & I year & $4.03 \pm 1.20$ & $1.16(0.93-2.01)$ & $1.10 \pm 0.28$ & $2.36 \pm 0.79$ & $1.20 \pm 0.24$ & $0.77 \pm 0.20$ \\
\hline P5 & - & 0.760 & 0.228 & 0.068 & 0.893 & 0.025 & 0.126 \\
\hline P6 & - & 0.525 & 0.992 & 0.059 & 0.697 & 0.028 & 0.350 \\
\hline P7 & - & 0.971 & 0.318 & 0.766 & 0.690 & 0.985 & 0.831 \\
\hline P8 & - & $0.78 I$ & 0.654 & 0.690 & 0.678 & 0.800 & 0.496 \\
\hline
\end{tabular}

Notes: PI; difference in lipid levels across genotypes at baseline (tested by analysis of covariance. Sex, age, BMI, blood pressure, alcohol consumption, and cigarette smoking were adjusted for in the statistical analysis). P2; difference in lipid levels across genotypes measured at I year (tested by analysis of covariance. Sex, age, BMI, blood pressure, alcohol consumption, and cigarette smoking were adjusted for in the statistical analysis). P3; change in levels of serum lipids between baseline and I-year levels according to genotypes (tested by ANOVA). P4; change in levels of the serum lipid between baseline and I-year level according to genotypes (tested by analysis of covariance. Sex, age, BMI, blood pressure, alcohol consumption, and cigarette smoking were adjusted for in the statistical analysis). P5; difference in lipid levels between the CC genotype and T-allele at baseline (tested by analysis of covariance. Sex, age, BMI, blood pressure, alcohol consumption, and cigarette smoking were adjusted for in the statistical analysis). P6; difference in lipid levels between the CC genotype and T-allele measured at I year (tested by analysis of covariance. Sex, age, BMI, blood pressure, alcohol consumption, and cigarette smoking were adjusted for in the statistical analysis). P7; change in levels of the serum lipid between baseline- and I-year levels according to the T-allele and the CC genotype (tested by ANOVA). P8; change in levels of the serum lipid between baseline- and I-year levels according to the T-allele and the CC genotype adjusted for covariates (tested by analysis of covariance. Sex, age, BMI, blood pressure, alcohol consumption, and cigarette smoking were adjusted for in the statistical analysis). TG did not follow a normal distribution; the values are expressed as medians (25th and 75th percentiles) and were log-transformed for the analysis.

Abbreviations: TC, total cholesterol; TGs, triglycerides; HDL-C, high-density lipoprotein cholesterol; LDL-C, low-density lipoprotein cholesterol; ApoAI, apolipoprotein Al; ApoB, apolipoprotein B.

ApoB levels in response to atorvastatin in females but not in males. Female individuals carrying the rs5888 T-allele (CT and TT) had a greater reduction in TC, LDL-C and ApoB after $20 \mathrm{mg}$ /day atorvastatin. These significant gene-statin interaction effects on serum lipid levels were also previously found in Brazilian hypercholesterolemic individuals treated with atorvastatin. ${ }^{13}$ Similar to the results in females in the present study, the previous study showed that hypercholesterolemic c.1050 TT (rs5888) genotype carriers had larger changes in TC, LDL-C, and apoB than $\mathrm{C}$ allele carriers (CC and $\mathrm{CT}$ genotypes) in response to atorvastatin; however, the authors of the previous study did not perform a stratified analysis based on sex, and it should be noted that $67 \%$ of the hypercholesterolemic subjects were women. The positive results in the Brazilian population were mainly from the female population. Therefore, the rs5888 SNP may interact with statins to play a role in lipid metabolism in females, although the mechanism of this possible role is unknown. However, estrogen receptors (ERs) ( $\alpha$ and $\beta$ ) or their polymorphisms are involved in the response to lipidlowering therapy ${ }^{34,35}$ Chiba-Falek et al showed that estrogen and the $S C A R B 1$ genotype may act synergistically to regulate the expression of SCARB1 isoforms and impact serum levels of HDL-C and TGs. ${ }^{36}$ Therefore, the sex difference in the interaction between SCARB1 rs5888 and atorvastatin on serum lipid levels may be due to the interaction between SCARB1 and estrogen.

\section{Strengths and Limitations of the Study}

The present study is the first to describe the influence of the SCARB1 rs5888 SNP on the serum lipid response to atorvastatin in female patients with ACS undergoing PCI. However, there are several potential limitations in the present study. First, there were several diabetes patients in this study, but information on hypoglycemic drugs was missing; thus, interference by these drug therapies could not be analyzed or excluded. Second, the sample size of 
Table 6 Influence of the SCARBI Rs5888 SNP on Serum Lipid Levels in Response to Statins in Females

\begin{tabular}{|c|c|c|c|c|c|c|c|}
\hline Genotypes & Period & TC (mmol/L) & TG (mmol/L) & HDL-C (mmol/L) & LDL-C (mmol/L) & ApoAl (g/L) & ApoB (g/L) \\
\hline \multirow[t]{2}{*}{ CC (22) } & Baseline & $4.73 \pm 0.89$ & $1.26(0.96-2.13)$ & $1.19 \pm 0.35$ & $2.80 \pm 0.79$ & $1.20 \pm 0.33$ & $0.91 \pm 0.18$ \\
\hline & I year & $3.84 \pm 0.60$ & I.45 (0.93-I.89) & $1.14 \pm 0.18$ & $1.99 \pm 0.50$ & $1.25 \pm 0.12$ & $0.70 \pm 0.15$ \\
\hline \multirow[t]{2}{*}{ CT (24) } & Baseline & $5.69 \pm 1.25$ & I.48 (I.03-2.27) & $1.34 \pm 0.29$ & $3.59 \pm 1.11$ & $1.42 \pm 0.22$ & $1.07 \pm 0.29$ \\
\hline & I year & $4.15 \pm 0.83$ & $1.47(0.89-1.90)$ & $1.28 \pm 0.30$ & $2.33 \pm 0.62$ & $1.37 \pm 0.23$ & $0.76 \pm 0.19$ \\
\hline \multirow[t]{2}{*}{ TT (4) } & Baseline & $5.91 \pm 0.12$ & I.88 (0.83-2.92) & $1.09 \pm 0.13$ & $3.95 \pm 0.07$ & $1.05 \pm 0.12$ & $1.19 \pm 0.15$ \\
\hline & I year & $4.13 \pm 0.21$ & $0.8 \mathrm{I}(0.75-0.87)$ & $1.24 \pm 0.07$ & $2.44 \pm 0.12$ & $1.27 \pm 0.10$ & $0.78 \pm 0.03$ \\
\hline PI & - & 0.005 & 0.924 & 0.115 & 0.010 & 0.007 & 0.024 \\
\hline P2 & - & 0.291 & 0.058 & 0.174 & 0.073 & 0.073 & 0.348 \\
\hline P3 & - & 0.048 & 0.074 & 0.213 & 0.183 & 0.080 & 0.075 \\
\hline P4 & - & 0.043 & 0.105 & 0.192 & 0.189 & 0.096 & 0.064 \\
\hline \multirow[t]{2}{*}{ CT/TT (28) } & Baseline & $5.72 \pm 1.16$ & I.48 (0.95-2.28) & $1.31 \pm 0.29$ & $3.64 \pm 1.04$ & $1.37 \pm 0.25$ & $1.09 \pm 0.27$ \\
\hline & I year & $4.15 \pm 0.77$ & $1.42(0.82-1.58)$ & $1.27 \pm 0.28$ & $2.35 \pm 0.57$ & $1.35 \pm 0.22$ & $0.76 \pm 0.17$ \\
\hline P5 & - & 0.001 & 0.698 & 0.198 & 0.003 & 0.045 & 0.007 \\
\hline P6 & - & 0.116 & 0.299 & 0.067 & 0.022 & 0.048 & 0.147 \\
\hline P7 & - & 0.016 & 0.169 & 0.850 & 0.046 & 0.237 & 0.043 \\
\hline P8 & - & 0.012 & 0.135 & 0.859 & 0.047 & 0.260 & 0.020 \\
\hline
\end{tabular}

Notes: PI; difference in lipid levels across genotypes at baseline (tested by analysis of covariance. Sex, age, BMI, blood pressure, alcohol consumption, and cigarette smoking were adjusted for in the statistical analysis). P2; difference in lipid levels across genotypes measured at I year (tested by analysis of covariance. Sex, age, BMI, blood pressure, alcohol consumption, and cigarette smoking were adjusted for in the statistical analysis). P3; change in levels of serum lipids between baseline and I-year levels according to genotypes (tested by ANOVA). P4; change in levels of the serum lipid between baseline and I-year level according to genotypes (tested by analysis of covariance. Sex, age, BMI, blood pressure, alcohol consumption, and cigarette smoking were adjusted for in the statistical analysis). P5; difference in lipid levels between the CC genotype and T-allele at baseline (tested by analysis of covariance. Sex, age, BMI, blood pressure, alcohol consumption, and cigarette smoking were adjusted for in the statistical analysis). P6; difference in lipid levels between the CC genotype and T-allele measured at I year (tested by analysis of covariance. Sex, age, BMI, blood pressure, alcohol consumption, and cigarette smoking were adjusted for in the statistical analysis). P7; change in levels of the serum lipid between baseline- and I-year levels according to the T-allele and the CC genotype (tested by ANOVA). P8; change in levels of the serum lipid between baseline- and I-year levels according to the T-allele and the CC genotype adjusted for covariates (tested by analysis of covariance. Sex, age, BMI, blood pressure, alcohol consumption, and cigarette smoking were adjusted for in the statistical analysis). TG did not follow a normal distribution; the values are expressed as medians (25th and 75th percentiles) and were log-transformed for the analysis.

Abbreviations: TC, total cholesterol; TGs, triglycerides; HDL-C, high-density lipoprotein cholesterol; LDL-C, low-density lipoprotein cholesterol; ApoAl, apolipoprotein $\mathrm{Al}$; ApoB, apolipoprotein B.

females was slightly small and not equal to the number of males, which could have biased the results; therefore, a large study population with sufficient power is required to duplicate these results.

\section{Conclusion}

This study indicates that there is a sex-specific influence of the SCARB1 rs5888 SNP on the serum lipid response to atorvastatin in patients with ACS undergoing PCI. The $S C A R B 1$ rs5888 T-allele is associated with a greater reduction in serum TC, LDL-C, and ApoB after atorvastatin treatment in female patients with ACS undergoing PCI.

\section{Ethics Approval and Consent to Participate}

This study complied with the Declaration of Helsinki and was approved by the Institutional Ethics Committee of People's Hospital of Guangxi Zhuang Autonomous
Region. Written informed consent was obtained from the participants.

\section{Author Contributions}

Dong-Feng $\mathrm{Wu}$ and Dan Lin contributed equally to this work. All authors made a significant contribution to the work reported, whether that is in the conception, study design, execution, acquisition of data, analysis and interpretation, or in all these areas; took part in drafting, revising or critically reviewing the article; gave final approval of the version to be published; have agreed on the journal to which the article has been submitted; and agree to be accountable for all aspects of the work.

\section{Funding}

This study was supported by the National Natural Science Foundation of China (No: 81660066), the Natural Science Foundation of Guangxi (No: 2016GXNSFBA380209), the Science and Technology Research Project of Guangxi 
Education Department (No: 2013LX040), and the Scientific Research and Technology Development Program of Guangxi (No: 1598012-2).

\section{Disclosure}

The authors have declared that they have no competing interests.

\section{References}

1. Castelli WP, Garrison RJ, Wilson PW, et al. Incidence of coronary heart disease and lipoprotein cholesterol levels. The Framingham Study. JAMA. 1986;256:2835-2838. doi:10.1001/jama.1986.033 80200073024

2. Gordon DJ, Probstfield JL, Garrison RJ, et al. High-density lipoprotein cholesterol and cardiovascular disease. Four prospective American studies. Circulation. 1989;79:8-15. doi:10.1161/01. CIR.79.1.8

3. Castelli WP, Anderson K, Wilson PW, Levy D. Lipids and risk of coronary heart disease. The Framingham Study. Ann Epidemiol. 1992;2(1-2):23-28. doi:10.1016/1047-2797(92)90033-M

4. Hague WE, Simes J, Kirby A, et al. Long-term effectiveness and safety of pravastatin in patients with coronary heart disease: sixteen years of follow-up of the LIPID Study. Circulation. 2016;133 (19):1851-1860. doi:10.1161/CIRCULATIONAHA.115.018580

5. Stone NJ, Robinson JG, Lichtenstein AH, et al. 2013 ACC/AHA guideline on the treatment of blood cholesterol to reduce atherosclerotic cardiovascular risk in adults: a report of the American College of Cardiology/American Heart Association Task Force on Practice Guidelines. J Am Coll Cardiol. 2014;63(25Pt B):2889-2934. doi:10.1016/j.jacc.2013.11.002

6. Postmus I, Verschuren JJ, de Craen AJ, et al. Pharmacogenetics of statins: achievements, whole-genome analyses and future perspectives. Pharmacogenomics. 2012;13(7):831-840. doi:10.2217/ pgs. 12.25

7. Chasman DI, Posada D, Subrahmanyan L, et al. Pharmacogenetic study of statin therapy and cholesterol reduction. JAMA. 2004;291 (23):2821-2827. doi:10.1001/jama.291.23.2821

8. Acton S, Rigotti A, Landschulz KT, et al. Identification of scavenger receptor SR-BI as a high density lipoprotein receptor. Science. 1996;271(5248):518-520. doi:10.1126/science.271.5248.518

9. Rigotti A, Trigatti BL, Penman M, et al. A targeted mutation in the murine gene encoding the high density lipoprotein (HDL) receptor scavenger receptor class B type I reveals its key role in HDL metabolism. Proc Natl Acad Sci USA. 1997;94(23):12610-12615. doi:10.1073/pnas.94.23.12610

10. West M, Greason E, Kolmakova A, et al. Scavenger receptor class B type I protein as an independent predictor of high-density lipoprotein cholesterol levels in subjects with hyperalphalipoproteinemia. J Clin Endocrinol Metab. 2009;94(4):1451-1457. doi:10.1210/ jc.2008-1223

11. Acton S, Osgood D, Donoghue M, et al. Association of polymorphisms at the SR-BI gene locus with plasma lipid levels and body mass index in a white population. Arterioscler Thromb Vasc Biol. 1999;19 (7):1734-1743. doi:10.1161/01.ATV.19.7.1734

12. Morabia A, Ross BM, Costanza MC, et al. Population-based study of SR-BI genetic variation and lipid profile. Atherosclerosis. 2004;175 (1):159-168. doi:10.1016/j.atherosclerosis.2004.03.014

13. Cerda Á, Genvigir FDV, Arazi SS, et al. Influence of SCARB1 polymorphisms on serum lipids of hypercholesterolemic individuals treated with atorvastatin. Clin Chim Acta. 2010;411(9-10):631-637. doi:10.1016/j.cca.2010.01.002
14. Wu DF, Yin RX, Hu XJ, et al. Association of rs5888 SNP in the scavenger receptor class B type 1 gene and serum lipid levels. Lipids Health Dis. 2012;11:50. doi:10.1186/1476-511X-11-50

15. Wu DF, Yin RX, Cao XL, et al. Scavenger receptor class B type 1 gene rs5888 single nucleotide polymorphism and the risk of coronary artery disease and ischemic stroke: a case-control study. Int $J$ Med Sci. 2013;10(12):1771-1777. doi:10.7150/ijms.7044

16. Xhyheri B, Bugiardini R. Diagnosis and treatment of heart disease: are women different from men? Prog Cardiovasc Dis. 2010;53 (3):227-236. doi:10.1016/j.pcad.2010.07.004

17. Wu DF, Wu YX, Deng JL. Changes in homocysteine levels affect serum lipid response to atorvastatin in patients with acute coronary syndrome: a Retrospective Observational Study. Clin Appl Thromb Hemost. 2020;26:1076029620920369. doi:10.1177/1076029620920369

18. Zhao P, Liu S, Zhong Z, Liu J. Age- and sex-related difference of lipid profile in patients with ischemic stroke in China. Medicine. 2018;97(23):e10930. doi:10.1097/MD.0000000000010930

19. Wei Y, Qi B, Xu J, et al. Age- and sex-related difference in lipid profiles of patients hospitalized with acute myocardial infarction in East China. J Clin Lipidol. 2014;8(6):562-567. doi:10.1016/j. jacl.2014.09.006

20. Mendelsohn ME, Karas RH. The protective effects of estrogen on the cardiovascular system. N Engl J Med. 1999;340(23):1801-1811.

21. Benjamin EJ, Blaha MJ, Chiuve SE, et al. Heart disease and stroke statistics-2017 update: a report from the American Heart Association. Circulation. 2017;135(10):e146-e603.

22. Taqueti VR. Sex differences in the coronary system. Adv Exp Med Biol. 2018;1065:257-278.

23. Vaccarino V, Badimon L, Corti R, et al. Ischaemic heart disease in women: are there sex differences in pathophysiology and risk factors? Position paper from the working group on coronary pathophysiology and microcirculation of the European Society of Cardiology. Cardiovasc Res. 2011;90(1):9-17. doi:10.1093/cvr/cvq394

24. Bush TL, Fried LP, Barrett-Connor E. Cholesterol, lipoproteins, and coronary heart disease in women. Clin Chem. 1988;34(8B):B60-B70.

25. Faubion SS, Kapoor E, Moyer AM, Hodis HN, Miller VM. Statin therapy: does sex matter? Menopause. 2019;26(12):1425-1435. doi:10.1097/GME.0000000000001412

26. Mombelli G, Bosisio R, Calabresi L, et al. Gender-related lipid and/or lipoprotein responses to statins in subjects in primary and secondary prevention. J Clin Lipidol. 2015;9(2):226-233. doi:10.1016/j.jacl.2014.12.003

27. Zhang R, Zhao L, Liang L, Xie G, Wu Y. Factors explaining the gender disparity in lipid-lowering treatment goal attainment rate in Chinese patients with statin therapy. Lipids Health Dis. 2012;11:59. doi:10.1186/1476-511X-11-59

28. Ansell BJ, Fonarow GC, Maki KC, et al. Reduced treatment success in lipid management among women with coronary heart disease or risk equivalents: results of a national survey. Am Heart J. 2006;152 (5):976-981. doi:10.1016/j.ahj.2006.05.013

29. Roberts CGP, Shen H, Mitchell BD, et al. Variants in scavenger receptor class B type I gene are associated with HDL cholesterol levels in younger women. Hum Hered. 2007;64(2):107-113. doi:10.1159/000101962

30. Osgood D, Corella D, Demissie S, et al. Genetic variation at the scavenger receptor class B type I gene locus determines plasma lipoprotein concentrations and particle size and interacts with type 2 diabetes: the framingham study. J Clin Endocrinol Metab. 2003;88 (6):2869-2879. doi:10.1210/jc.2002-021664

31. Hong SH, Kim Y-R, Yoon YM, et al. Association between HaeIII polymorphism of scavenger receptor class B type I gene and plasma HDL-cholesterol concentration. Ann Clin Biochem. 2002;39 (5):478-481. doi:10.1258/000456302320314485

32. Rejeb J, Omezzine A, Boumaiza I, et al. Association of three polymorphisms of scavenger receptor class BI gene (exon8, exon1, intron5) with coronary stenosis in a coronary Tunisian population. Gene. 2012;511(2):383-388. doi:10.1016/j.gene.2012.09.070 
33. Stanislovaitiene D, Lesauskaite V, Zaliuniene D, et al. SCARB1 single nucleotide polymorphism (rs5888) is associated with serum lipid profile and myocardial infarction in an age- and gender-dependent manner. Lipids Health Dis. 2013;12(1):24. doi:10.1186/1476-511X-12-24

34. Yoon M. PPAR $\alpha$ in obesity: sex difference and estrogen involvement. PPAR Res. 2010;2010:584296. doi:10.1155/2010/584296

35. Smiderle L, Fiegenbaum M, Hutz MH, et al. ESR1 polymorphisms and statin therapy: a sex-specific approach. Pharmacogenomics $J$. 2016;16(6):507-513. doi:10.1038/tpj.2015.60
36. Chiba-Falek O, Nichols M, Suchindran S, et al. Impact of gene variants on sex-specific regulation of human scavenger receptor class B type 1 (SR-BI) expression in liver and association with lipid levels in a population-based study. BMC Med Genet. 2010;11:9. doi:10.1186/1471-2350-11-9

\section{Publish your work in this journal}

Pharmacogenomics and Personalized Medicine is an international, peer-reviewed, open access journal characterizing the influence of genotype on pharmacology leading to the development of personalized treatment programs and individualized drug selection for improved safety, efficacy and sustainability. This journal is indexed on the American Chemical Society's Chemical Abstracts Service (CAS). The manuscript management system is completely online and includes a very quick and fair peer-review system, which is all easy to use. Visit http://www.dovepress.com/testimonials.php to read real quotes from published authors. 